NBER WORKING PAPER SERIES

\title{
MEANS-TESTED MORTGAGE MODIFICATION: HOMES SAVED OR INCOME DESTROYED?
}

\author{
Casey B. Mulligan \\ Working Paper 15281 \\ http://www.nber.org/papers/w15281 \\ NATIONAL BUREAU OF ECONOMIC RESEARCH \\ 1050 Massachusetts Avenue \\ Cambridge, MA 02138 \\ August 2009
}

I appreciate comments by Gary Becker, Kevin Murphy, a number of University of Chicago students, and conference participants at the University of Illinois Chicago Campus. I will provide updates on this work on my blog www.panic2008.net. The views expressed herein are those of the author(s) and do not necessarily reflect the views of the National Bureau of Economic Research.

NBER working papers are circulated for discussion and comment purposes. They have not been peerreviewed or been subject to the review by the NBER Board of Directors that accompanies official NBER publications.

(C) 2009 by Casey B. Mulligan. All rights reserved. Short sections of text, not to exceed two paragraphs, may be quoted without explicit permission provided that full credit, including $\odot$ notice, is given to the source. 
Means-Tested Mortgage Modification: Homes Saved or Income Destroyed?

Casey B. Mulligan

NBER Working Paper No. 15281

August 2009

JEL No. E24,H21,L11

\begin{abstract}
$\underline{\text { ABSTRACT }}$
This paper uses the theories of price discrimination and optimal taxation to investigate effects of underwater mortgages on foreclosures and the incentives to earn income, and the degree to which those effects are shaped by public policy. I find that the federal government's means-tested mortgage modification plan creates a massive implicit tax that may be significant even from a macroeconomic perspective. An alternative of modifying mortgages to maximize lender collections would also feature means tests, but with less effort distortion and perhaps fewer foreclosures. The paper also considers the consequences of a public policy that left mortgage modification to lenders, subject to a requirement that modification would not be conditioned on borrower income.
\end{abstract}

Casey B. Mulligan

University of Chicago

Department of Economics

1126 East 59th Street

Chicago, IL 60637

and NBER

c-mulligan@uchicago.edu 
By some measures, U.S. average housing prices have fallen by a third since 2006 and some forecast them to fall further. Prices have fallen more than fifty percent in Las Vegas and Phoenix, and nearly as much in Detroit, Miami and much of California. ${ }^{2}$ As a result, almost 14 million home mortgages nationwide were "underwater" in early 2009: the amount owed exceeded the market value of the collateral. ${ }^{3}$ About one third of home mortgages in Arizona, California, Florida, and Michigan, and more than one half of home mortgages in Nevada, were underwater.

At the same time, U.S. employment has plummeted, especially in states that had large housing price increases prior to 2006. ${ }^{4}$ Many factors - too many to be considered in a single paper - caused the 2008-9 recession, but the housing price cycle and its legacy of underwater mortgages is likely among them. This paper investigates some effects of underwater mortgages on foreclosures and the incentives to earn income, and the degree to which those effects are shaped by public policy.

\footnotetext{
${ }^{2}$ National and city-level housing price changes in this paragraph are for the Case-Shiller composite home price index.

${ }^{3}$ http://www.nytimes.com/2009/05/04/opinion/04mon2.html, http://www.reuters.com/article/bondsNews/idUSN2832609020090528. About one in four homes with mortgages were under water by 2009 Q2 (Levy, 2009).

${ }^{4}$ For example, employment from January 2006 to June 2009 fell by 6.9 (6.1) percent in Florida (Arizona) where housing prices had previously risen 96 (74) percent 2000-2005, as compared to the U.S. aggregate employment decline of 2.4 percent and prior housing price boom of 46 percent. State-level employment data is total nonfarm payrolls from www.bls.gov. Housing price changes cited in this footnote are calculated from the OFHEO index, which is available state-by-state, but tend to be less than changes in the Case-Shiller index.
} 


\section{Foreclosures as a Consequence of Negative Equity}

A homeowner always has the option to stop paying his mortgage. Although state laws are somewhat different, to a good approximation the worst case scenario for a homeowner who stops paying is that he can no longer own or occupy the house, and may suffer a reduction in his credit rating that might raise his costs of future borrowing. But if the combined value of the house and these costs were less than the present value of his promised mortgage payments, then he could do better than paying in full. That's probably an important reason why, as of early 2009, more than five million homes were already either in foreclosure (lenders were seizing the collateral as a consequence of lack of payment) or their owners were delinquent on their mortgage payments. ${ }^{5}$

When foreclosures are motivated by low home values rather than the quality of the match between a homeowner and his home, a foreclosure is inefficient because it requires the homeowner to live elsewhere. The anticipation of foreclosure of an underwater mortgage probably also creates moral hazard in maintaining the house, because the occupant prior to foreclosure has no stake in the home's value. These are some of the reasons why public policy seeks to reduce foreclosures.

In principle, lenders could create many of the proper incentives even without government intervention, by having homeowners be a claimant on the home's value at the margin. One conceptually simple way to achieve this is to write down the value of the mortgage so that it is less than or equal to the home's market value and the mortgage is no longer underwater. Once the mortgage was written down, the homeowner would have an incentive to continue paying the (written down) mortgage, or at least sell his home for maximum value in the marketplace to fully repay his (written down) mortgage.

\footnotetext{
${ }^{5}$ Note that "inability to pay" is probably not enough by itself to create a foreclosure (Foote et al, 2009, footnote 3), because a homeowner unable to pay but with positive home equity may want to sell his home to pay the loan (and thereby retain his home equity) rather than invite foreclosure. Liebowitz (2009) finds that negative equity was a more important factor than unemployment in causing the foreclosures that occurred in the second half of 2008. Geanakopolos and Koniak (2009) find that foreclosures are "stunningly sensitive" to the amount of home equity.
} 
Lenders have modified the terms of some of their mortgages or otherwise modified payments associated with mortgages in order to avoid foreclosure, both in this recession and previous recessions. ${ }^{6}$ However, some mortgage industry participants have complained that too few mortgage modifications occur because of the excessive transaction costs in dealing with individual homeowner situations and dealing with investors who have varied stakes in the mortgage payments. ${ }^{7}$

\section{Public Sector Modification Formulas Feature Marginal Tax Rates in Excess of 100\%}

The Bush Administration took steps to streamline the consideration of individual homeowner circumstances. In 2008, the Federal Deposit Insurance Corporation (FDIC), Federal National Mortgage Association, and the Federal Home Loan Mortgage Corporation all announced debt forgiveness or "loan modification" formulas. The Obama Administration continued this work with its "Homeowner Affordability and Stability Plan" (HASP) by offering subsidies to mortgage servicers and brokers who participate in mortgage modifications.

The FDIC's early plan said "Modifications would be designed to achieve sustainable payments at a 38 percent debt-to-income ratio of principal, interest, taxes, and insurance." (FDIC, 2008) Several major mortgage servicers such as Bank of America, JPMorgan Chase and Citigroup used those formulas for some of their delinquent borrowers. For example, Citigroup and the U.S. Treasury announced November $24^{\text {th }}$, 2008:

"Citigroup will modify mortgages to help people avoid foreclosure along the lines of an FDIC plan that was put into effect at IndyMac Bank... struggling home borrowers pay interest rates of about three percent for five years. Rates are reduced so that borrowers aren't paying more than 38 percent of their pretax income on housing." (Aversa, 2008)

\footnotetext{
${ }^{6}$ Sichelman (2001) discusses modifications during the 2001 recession. In their study of 32 million mortgages, the Office of Thrift Supervision (2009) found that about three percent were either modified or put on a payment plan during 2008, although the three percent double-counts mortgages that received multiple home retention actions during the year. Modification have occurred at a higher rate in 2009, and the Obama administration intends to modify several million of them.

${ }^{7}$ Eggert (2007), Geanakoplos and Koniak (2008). Nevertheless, most servicers are permitted to modify loans (Foote et al, 2009). Foote et al (2009) even find that the propensity to modify mortgages is uncorrelated with whether the mortgages are owned by the servicer.
} 
The Obama Administration has proposed essentially the same formula, except that housing costs would be limited to 31 (rather than 38) percent of pretax income. Hereafter, I refer to these two plans collectively as FDIC-HASP.

The FDIC-HASP plan massively distorts the supply of income-earning efforts, because its mortgage modification is large and means-tested: its formula implies that an action taken by a borrower to increase his income would increase his housing payment obligation by 31 percent of the income increment. ${ }^{8}$ If the affordable payment (i.e., the payment that would comprise 31 percent of income) were re-evaluated monthly, this would amount to a 31 percent marginal tax rate in each month that a modification could occur.

Standard practice determines an affordable payment based on the most recent year's income, and puts that payment in place for five years (recall the Citigroup practice cited above). Thus, a marginal dollar earned in the base year raises mortgage payment obligations by 31 cents in each of the following five years. If, say, 2009 income were used to calculate an affordable payment for the years 2010-14 and the interest rate were zero, then the marginal tax rate would be 155 percent for 2009 (5 times the formula's 0.31 limit on the payment to income ratio) and zero thereafter. Hereafter I assume an annual interest rate of 6 percent, which means that the marginal tax rate would be 131 percent for 2009. 9 Moreover, underwater mortgages are ubiquitous enough that FDICHASP mortgage modification could produce distortions that are large enough to be visible in the national employment data, or at least visible in the employment data of the

\footnotetext{
${ }^{8}$ It is well known that the common practice of collecting college tuition according to ability to pay creates work disincentives. Dick and Edlin (1997) estimated that college tuitions with annual list prices in the range $\$ 5,000$ - $\$ 10,000$ created marginal income tax rates in the range of $2-16$ percent. As ratios to potential income, these amounts are small compared to the amounts mortgage lenders have to collect today. Thus, it should be no surprise that underwater mortgage debt collection creates large marginal tax rates. ${ }^{9}$ Expressed as a percentage, the marginal tax rate is $31 \sum_{t=1}^{5}\left(\frac{1}{1.06}\right)^{t}=131$. To the extent that payment reductions last more than five years - U.S. Treasury (2009, pp. 2-3) has said "[the] lower interest rate must be kept in place for five years, after which it could gradually be stepped up to the conforming loan rate in place at the time of the modification." - the marginal tax rate would be even larger. The personal income tax treatment of mortgage modification could also affect a modification's implicit marginal tax rate. For the purpose of this paper, the finding that the rate exceeds 100 percent is more critical than its magnitude.
} 
worse hit states. Means-tested mortgage modification has created a massive implicit tax that is significant even from a macroeconomic perspective. ${ }^{10}$

\section{Related Literature and Outline of this Paper}

The purpose of this paper is to determine the degree to which it is in lenders' and the public's interest to adopt collection policies that create moral hazard in the labor market in order to reduce foreclosures in the housing market. The paper compares housing and labor market outcomes under three collection policies: (a) FDIC-HASP's means-tests, (b) the policy that maximizes collections, and (c) the policy that maximizes collections subject to the "non-discrimination" constraint that modifications are not conditioned on borrower income. The first two collection policies create, to varying degrees, moral hazard in the labor market, whereas the last does not.

The collection-maximizing policy is characterized by posing the collection problem as an optimal price discrimination program, and using the tools of optimal tax theory to characterize the solution. ${ }^{11}$ It is quite possible that the means-tested mortgage modification policy that maximizes lender objectives would - relative to a world where mortgage modification is not conditioned on borrower income - harm the public interest and have little impact on foreclosures. ${ }^{12}$ Moreover, marginal tax rates on the order of 130 percent - present in the FDIC-HASP plan - are beyond those that maximize collections, and further harm the public interest. The FDIC-HASP plan in many cases creates more foreclosures than do the policies that maximize collections, with or without means tests.

\footnotetext{
${ }^{10}$ Foote et al (2008, p. 243 and footnote 29) point out that "modification leads to a serious moral hazard problem" and that even homeowners who are not certain that modification will be available may still react to the possible means-test by not working, because the modification rewards for low income are so large. Some affected borrowers may not have anticipated that they would face a marginal tax rate in excess of $100 \%$. However, if borrowers generally understand that creditors will sometimes modify according to ability-to-pay but do not know exactly when a modification formula will apply, then some borrowers may behave ex ante as if they faced a high marginal tax rate even though ex poste they received no forgiveness.

${ }^{11}$ Grochulski (2008) models personal bankruptcy negotiations as a mechanism design problem akin to Mirrlees (1971), but Grochulski's study is "not designed to replicate any particular set of facts about the structure of actual credit markets or bankruptcy laws," (p. 29). Mulligan (2008) uses a Mirrlees approach (with two types) to relate unsecured debt collection to employment 1929-33 and 2008. Neither of these papers report results related to the tradeoff between foreclosures and moral hazard in the labor market, and how public policies affect those tradeoffs.

12 This result is reminiscent of Chiang and Spatt's (1982) finding that third-degree price discrimination can result in less welfare than no discrimination, although they find this possibility because (unlike here) they
} 
Kahn and Yavas (1994) is an early paper modeling foreclosures as the "outside option" in a mortgage renegotiation. This aspect of renegotiation was studied further by Livshits et al (2007), White and Zhu (2008), but still considering borrower income as an exogenous characteristic - and therefore not studying the tradeoff between foreclosures and moral hazard in the labor market. Han and Li (2007) consider the combined wealth and substitution effects of mortgage modification on labor supply, but do not attempt to separate them or calculate a labor market deadweight cost of modifications. Given that the "wealth" effect of writing down a mortgage is a transfer from lenders to borrowers, netting out the wealth effect is important even for positive analysis of the aggregate effects.

Fisher (1933), Mishkin (1978), Bernanke and Gertler (1983), Kroszner (1999) and others have noted that household balance sheets seem to be correlated with the business cycle and have offered theoretical interpretations of this correlation. However, their models operate on an investment or intertemporal margin, whereas my model operates on the consumption-effort margin. They model a problem with the intermediation of new loans, whereas I model a problem with settling the old ones.

Section I begins by deriving the budget set facing borrowers who might be eligible for mortgage modification according to the FDIC-HASP formula. The budget set vividly illustrates how means-tested modification can destroy income-earning incentives. Section II models the economic environment, and shows how the collection-maximizing modification policy is a special case of mechanism design or optimal tax theory. The supplies of income earning effort under the three collection policies are derived and compared in Section III. Section IV derives and compares foreclosure rates under the three collection policies. Section V concludes.

have two dimensions of unobserved heterogeneity: price discrimination correlated with one dimension can harm sorting in the other. 


\section{The Budget Set of a Borrower Facing the FDIC-HASP Modification Formula}

In order to see more precisely how means-tested mortgage modification affects incentives, it helps to consider the shape of borrower budget sets with and without means-tested mortgage modification. Let time $t=0$ be the period (some time after the loan was granted) during which income is measured for the purpose of modification, which modifies loan payments in periods $t=1,2, \ldots$. At times $t=0,1, \ldots$, the borrower consumes $c_{t}$ at and expends effort $n_{t}$. Effort $n_{t}$ produces taxable income - that is, income that can be observed by the lender ${ }^{13}-$ in the amount $n_{t} w_{t}$. The entire commodity space is $\left\{c_{0}, n_{0}, c_{1}, n_{1}, c_{2}, n_{2}, \ldots\right\}$, but analysis of it can be simplified by assuming a present value budget constraint and considering the tradeoff between effort at time zero (hereafter, $n$ ) and the present value of all other expenditure (hereafter, $c$ ). $a$ denotes the amount that could be consumed if period zero income were zero and home equity were zero.

\section{I.A. Foreclosure Costs}

Consider three scenarios for the borrower: (i) payments are made in full (according to the loan's original terms), (ii) he walks away from the home and mortgage, or (iii) the bank unconditionally writes down his mortgage so that it is no longer underwater. $^{14}$ Each scenario by itself presents the borrower with a linear budget constraint with slope -1 (see Figure 1, in which borrow income $n w$ is shown increasing from right to left), but the scenarios differ in terms of the budget constraint's intercept. Because the mortgage is underwater, the full payment scenario (i) has intercept closer to

\footnotetext{
${ }^{13}$ In practice, lenders consider borrower personal income tax returns, which means that the income concept relevant for mortgage modification is similar in character and timing to the taxable income relevant for income tax policy analysis. Thus, effort includes not only hours worked but also truthful reporting to the IRS, occupational choice, etc. (Feldstein, 1999)

${ }^{14}$ In practice, mortgages are modified by some or all of the following: (i) reduced interest rate, (ii) reduced principal, postponement (without interest) of delinquent principal and interest payments, (iv) extended amortization (Sichelman, 2001; U.S. Treasury, February 2009). For my purposes - analysis of the consequences of a presumably permanent housing price crash -- all of these can be summarized in terms of the present value of payments to be made after the loan is modified (Kahn and Yavas, 1994, also take this approach). Modifications that result from temporary shocks could have different effects depending on whether principal or interest is modified (Foote et al, 2009).
} 
the origin than the write-down scenario (iii). Under the foreclosure scenario ${ }^{15}$ (ii), the homeowner surrenders the house, has his mortgage erased, and incurs foreclosure costs.

Foreclosure costs include moving costs, the moral hazard related to maintenance (created when a home's occupant is not its owner), and lost access to credit markets. ${ }^{16}$ The $c$-intercept of the foreclosure scenario (ii) is closer to the origin than the write-down scenario (iii) by the amount of foreclosure costs, but its position relative to the full payment scenario depends on the relative comparison of the amount underwater and the amount of foreclosure costs. If all borrowers had foreclosure costs that exceeded the amount underwater, then all borrowers would prefer to pay in full than to be foreclosed. The interesting cases have a significant number of borrowers for whom the amount underwater is greater than the foreclosure cost: in terms of Figure 1, the foreclosure scenario has intercept in between those of the other two scenarios.

\section{I.B. Means-tests}

Figure 2 shows how means-tested modification presents the borrower with a budget constraint in the $[-n w, c]$ plane that is in between the solid line and the outside dashed line in Figure 1 (the straight solid and dashed lines are identical in the two figures). Consider first the allocation $X$ in which the borrower puts forth no effort (in period zero) and consumes the amount $a-b$ while making full mortgage payments. At the allocation $Z$, the borrower also puts forth no effort, but makes no payments and is foreclosed. At the allocation $Z_{0}$, the mortgage is written down so that it is no longer underwater; the distance between $X$ and $Z_{0}$ is the amount underwater, $b$.

\footnotetext{
${ }^{15}$ Because the mortgage is assumed to be under water, I do not distinguish between foreclosure, "walking away," and "deed in lieu of foreclosure." I refer to all three as "foreclosure" and assume that they result in the payment of deadweight "foreclosure costs."

${ }^{16}$ I model foreclosure costs as if they are entirely paid by borrowers. This is just a normalization, achieved by defining the amount of negative equity $b$ to be the par value of the mortgage minus the value of the home to the bank in the case of foreclosure.
} 
At allocation $X$, (period 0$)$ income is zero and mortgage payments are made in full, which means that mortgage payments are more than 31 percent of income. The allocation $Y$ indicates the amount of effort that must be supplied in order for the borrower to have income that equals $y_{Y} \equiv$ (full housing payments)/0.31 (that is, full housing payments are equal to 31 percent of income). Thus, under the FDIC-HASP modification, no allocation to the left of $Y$ would be eligible for modification. The budget constraint for underwater borrowers therefore includes the segment $O Y$.

The borrower's budget set has to include the allocation $Z$, because foreclosure and not working are among his options. Even without knowing the exact location of the budget set's boundary between allocation $Y$ and $Z$, we know that (unlike the segment $O Y$ ) its average slope has to be less than one in magnitude. This on-average flattening of the budget constraint's slope is the fundamental reason why means-tested mortgage modification reduces incentives to earn the income that would be used in the modification formula.

As noted above, at point $Y$, the present value of mortgage payments falls $\$ 1.31$ for each dollar that income is reduced. Because consumption is income minus mortgage payments, consumption therefore increases $\$ 0.31$ for each dollar that income falls. ${ }^{17}$ The $31 \%$ mortgage modification formula therefore creates an upward sloping budget constraint slope, at least for incomes near and below the income corresponding to allocation $Y$.

\section{I.C. The Minimum Income Threshold}

The Bush and Obama Administrations have not provided modification formula details for incomes far below the income corresponding to allocation $Y$, but a few things are clear. First, the upward slope rarely continues to the point where income is zero, because that would involve eliminating all mortgage payments for five years, which in most cases would cause the present value of the modified mortgage's payments to be

\footnotetext{
${ }^{17}$ It is coincidence and rounding error that the slope of the budget constraint is equal to the percentage used in the mortgage modification rule. For example, a percentage of 38 (as under the Bush Administration) implies an implicit tax rate of $160 \%$ and budget constraint slope of +0.6 .
} 
significantly less than the home's market value. ${ }^{18}$ Given that allocations above and to the right of the outside dashed line would make the lender worse off than would foreclosure, it is unlikely that mortgage modification would present borrowers with a budget constraint that included such allocations. A good guess is that there is a threshold income $y_{W}$ with two properties: (i) underwater mortgages are eligible for modification if and only the borrower's income is in between $y_{W}$ and $y_{Y}$, and (ii) the amount paid by borrowers with exactly income $y_{W}$ is at least equal to the market value of the house. ${ }^{19}$

Figure 2 draws the case in which borrowers earning at the lower income threshold pay exactly the market value of the house; the allocation $W_{0}$ indicates the allocation where the income earned is such that exactly $b$ must be written down in order for mortgage payments to be reduced enough that housing payments are 31 percent of income. ${ }^{20}$ The complete budget constraint is $O Y W_{0} W Z$.

Section $W W_{0} Z$ of the budget constraint depends on the foreclosure cost, and therefore may vary across borrowers, even among borrowers with the same $b$. The length of segment $W_{0} W$ is equal to the amount of the foreclosure cost.

\section{I.D. Borrower Reactions to FDIC-HASP}

Assuming that borrower indifference curves slope down in the plane shown in Figure 2 (and ignoring optimization error), the distribution of repayments net of home values induced by budget constraint is $O Y W_{0} W Z$ is degenerate, with all of its mass at two points: 0 and $b$. Some of the borrowers repaying zero would have the unsecured part of their mortgages written down by $b$, the others would choose the foreclosure option. The induced income distribution would also have a mass point (corresponding to the lower income threshold), and would have holes both to the right and left of that mass point.

\footnotetext{
${ }^{18}$ A mortgage with 25 years remaining and rate fixed at six percent has about one third of the present value of its remaining payments come due during the first five years.

${ }^{19}$ I have seen press reports that some borrowers are being denied modification because their incomes are too low. More recently, the press has also reported (Rucker, 2009) that the Obama Administration may propose to allow unemployed people to become renters in their own home. If those people had an underwater mortgage, that would be represented in Figure 2 as including the allocation $Z_{0}$ as part of the budget set.

${ }^{20}$ A larger amount for the lower income threshold would shorten the segment $Y W_{0}$ so that it ends below the outer dashed line.
} 
As compared to a world with no mortgage modification (lenders foreclose on anyone paying less than the full amount of the loan), the FDIC-HASP plan reduces foreclosures by inducing some of those with $m<b$ to choose the point $W_{0}$, rather than foreclosure, which would be an allocation somewhere on the linear extension of the segment $W Z$ in Figure 2. However, the FDIC-HASP plan does not necessarily eliminate foreclosures, because some borrowers may prefer an allocation on the segment $W Z$ to the point $W_{0}$.

With the exception of point $W_{0}$, any utility-maximizing choice on the segments $Y W_{0}$ or $W_{0} W$ is socially inefficient because it does not equate $w$ to the marginal rate of substitution between $c$ and $n$. Even at $W_{0}$, the marginal rate of substitution would equal one only by an unlikely coincidence: many other marginal rates of substitution are also consistent with an optimal choice $W_{0}$.

FDIC-HASP will likely induce too little effort, because (as noted above) the average slope is less than one in magnitude on the section $Y W_{0} W Z$. However, depending on the relative size of the foreclosure costs and the amount underwater, as compared to the slopes of indifference curves, it is possible that some borrowers would increase their effort in order to earn above the minimum threshold and thereby be eligible for modification. This outcome is impossible if the allocation $W_{0}$ is on the segment $X Z_{0}$, or if the threshold income associated with $W_{0}$ is enough higher than shown in Figure 2 (so that the allocation $W_{0}$ is at or below the dashed line). ${ }^{21}$

\section{A Simple Model of Foreclosure, Debt Forgiveness and Effort Distortions}

\section{I.A. Setup and Outcomes without Means-tests}

Each individual of a group of ex ante identical borrowers obtains a collateralized loan. Initially, the value of the collateral exceeds the amount lent. Some time after the beginning of the loan, but before its final payment, the borrowers experience a common change in their collateral value. Of particular interest is the case in which collateral values fall short of the amount owed. I let $b$ denote the amount of negative home equity,

\footnotetext{
${ }^{21}$ The income associated with allocation $W$ is less than the income associated with $Y$. Allocation $Y$ is associated with a house payment-income ratio of 0.31 , which itself is greater than the actual ratio for most borrowers. Thus, section $O Y W_{0}$ is more relevant for most borrowers choices than is segment $W_{0} W$.
} 
which is sometimes referred to as the "amount underwater" or the "unsecured part of the mortgage."

In addition, each borrower has received an idiosyncratic shock to his privately observed labor productivity $w$. Distribution of productivities resulting from those shocks is $F$, with density $f$ and support $\left[w_{L}, w_{H}\right]$. I assume that $F$ 's inverse Mills ratio has an elasticity greater than minus one. ${ }^{22}$

Each individual produces the product of his effort $n$ and his productivity $w$. Each individual has a utility function $u(c, n)$ defined over consumption $c$ and work effort $n$. Following much of the literature on the optimal taxation of heterogeneous agents, I assume that $u(c, n)$ is additively separable and satisfies the Spence-Mirrlees condition. ${ }^{23}$ Some of that literature also assumes that the function is quasilinear in $c$ - an assumption that is even more realistic here because $c$ is a broad composite of many goods, including leisure time at future dates. ${ }^{24}$ I therefore use the function:

$$
u(c, n)=c-\gamma^{\phi} \frac{n^{1+\phi}}{1+\phi}
$$

where $\gamma>0$ and $\phi \geq 0$ are constants. $1 / \phi$ is often interpreted as the inverse of the elasticity of effort supply $n$ with respect to productivity $w$ : the efficient effort supply is $n^{*}(w)=w^{1 / \phi} / \gamma$. Given that $\phi \geq 0$, the Spence-Mirrlees condition is necessarily satisfied. Note that I do not restrict the magnitude of the effort supply elasticity, except that it be positive. $^{25}$

Without means tests, borrowers have simply the choice of foreclosure or paying the amount $x \leq b$ requested by their lender. Such a borrower $i$ has budget constraint:

${ }^{22}$ This weak restriction is equivalent to $\frac{d}{d w}\left[w \frac{f(w)}{1-F(w)}\right]>0$. It is satisfied, for example, by the logistic distribution and the uniform distribution.

${ }^{23}$ See Salanié (2003, pp. 87-88), including an analysis of the Spence-Mirrlees condition for the quasilinear case.

${ }^{24}$ See, for example, Mulligan (2001), Ljungqvist and Sargent (2007), and Chetty and Saez (2009). A utility function that recognized wealth effects on effort would find them from transfers between borrowers and lenders, which would be exaggerated relative to a more realistic (and complicated) setup in which borrowers owned shares in the banks that were doing the lending.

${ }^{25}$ In particular, I do not assume that means tests necessarily have a large effort effect. Moreover, a small effort effects can have large deadweight costs. 


$$
c_{i}=a_{i}+w_{i} n_{i}-\min \left\{m_{i}, x\right\}
$$

where $a$ represents sources of full income other than effort during the period in question and $m_{i}>0$ denotes borrow $i$ 's foreclosure cost (" $m$ " is for "moving"). ${ }^{26}$ The crosssectional distribution of foreclosure costs is denoted $G$.

The borrower's choice to repay $x$ or incur $m_{i}$ has efficiency consequences. $m_{i}$ is a deadweight cost, whereas $x$ is a transfer from borrower to lender. Reduction in the amount $x$ to be repaid is one way that borrowers could be induced to repay rather than choose foreclosure: fraction of borrowers who prefer repaying $x$ rather than foreclosure is $1-G(x)$.

In other words, lenders face a tradeoff between the unsecured amount $x$ to be repaid and the fraction 1-G(x) of borrowers who repay. As shown by Figure 3's monotone curve, the mirror image of the foreclosure cost CDF illustrates the tradeoff because it maps payment amounts on the vertical axis to the fraction of borrowers on the horizontal axis who would prefer that payment amount to their foreclosure cost. In other words, the lender's choice of repayment amount is a choice of a point on that "demand curve." Unsecured debt collection therefore has a lot of analytics in common with the standard model of monopoly pricing where a monopolist faces a tradeoff between the amount sold and the profit obtained from each unit sold.

Assuming that the constraint $x \leq b$ does not bind, the single unsecured repayment amount maximizing lender-collections is $x_{0}$, where $x_{0}$ (not shown in Figure 3) satisfies a familiar unit-elastic condition: ${ }^{27}$

$$
\frac{G^{\prime}\left(x_{0}\right) x_{0}}{1-G\left(x_{0}\right)} \equiv 1
$$

Without discriminating, the collection maximizing foreclosure rate is $G\left(x_{0}\right)$.

\footnotetext{
${ }^{26}$ I assume that foreclosure costs are nonnegative. If some borrowers had a negative foreclosure cost, than foreclosure would be efficient for them.

${ }^{27}$ The possible corner solutions for $x_{0}$ are $b$ and the lower support of the distribution $G$.
} 
The non-discrimination outcome has two interesting properties. First, a lender chooses to write down everyone's debt (that is, set $x_{0}<b$ ) when $\frac{G^{\prime}(b) b}{1-G(b)}<1$. Second, for those lenders that choose to write down everyone's debt, the preferred amount of foreclosure depends on the shape of the foreclosure cost distribution $G$, and not the amount $b$ that mortgages are unsecured. These results are used below to compare collection-maximizing outcomes to outcomes under FDIC-HASP.

\section{I.B. Debt Forgiveness as Mechanism Design}

Because each borrower has the choice of foreclosure and making the payment $x$ requested by the lender, and borrowers are different, lenders could benefit (relative to the non-discrimination outcome above) by determining which borrowers have the high foreclosure costs and asking them to repay more. The foreclosure rate is zero in this case because the lender is better off collecting $m_{i}>0$ from borrower $i$ than foreclosing. This "perfect discrimination" case proves that it is possible for a discriminating debt collection policy to reduce foreclosures from what they would be without discrimination.

To the degree that foreclosure costs are private information, perfect discrimination may not be feasible. This makes the lender's collection-maximization problem a case of optimal third-degree price discrimination, or more generally a case of optimal mechanism design. Here I consider the environment - familiar from the optimal tax literature - in which each borrower's effort $n$ and foreclosure cost $m$ are private information, but his income wn is public. Henceforth, I also assume that the private information is one-dimensional: foreclosure costs are a monotone, increasing, and continuous function $m(w)$ of productivity. ${ }^{28}$ In determining the required payments to avoid foreclosure, lenders can discriminate among borrowers on the basis of the amount of home equity $-b$ and the amount of their income $w n$.

For each group of borrowers with the same home equity, the amount of revenue collected on the unsecured part of their mortgages is:

\footnotetext{
${ }^{28}$ To the degree that foreclosure costs are costs of nonmarket time and hassle, they would increase with market productivity $w$. It is also possible that higher productivity individuals place a greater absolute value on future credit market access, because they expect their future credit market transactions to be of greater dollar amounts.
} 


$$
\int_{0}^{\infty} x(y) d H(y)
$$

where $y$ is income, $x(y)$ is the payment schedule, and $H$ is the income distribution. As is well known in the mechanism design literature, this statement of the lender's collection problem is pretty intractable because the income distribution $H$ depends on the payment schedule. The revelation principle permits an equivalent statement of the problem in the space of productivities. In this version, each type $w$ is assigned an amount of effort $n(w)$ and an amount to repay $x(w)$. Total collections are the aggregate of the collections from each type:

$$
\int_{w_{L}}^{w_{H}} x(w) f(w) d w
$$

Participation constraints (6) say that each $w$ of those making a payment prefers his allocation $\{n(w), x(w)\}$ to both foreclosure and paying in full:

$$
\begin{gathered}
u(a+w n(w)-x(w), n(w)) \geq \bar{u}(w) \\
\bar{u}(w) \equiv \max u(a+w n-\min \{m(w), b\}, n) \text { given } m(w), a, b
\end{gathered}
$$

where $u$ is the utility function (1). As indicated, the outside option depends on the cost of foreclosure $m(w)$ and the par value $b$ of the unsecured part of the loan.

A series (7) of incentive constraints require that each borrower prefer his allocation (which is his choice between the modification and effort assigned to him, or paying in full, or foreclosure) to earning the income associated with some other modified payment: 


$$
\begin{gathered}
\max \{u(a+w n(w)-x(w), n(w)), \bar{u}(w)\} \geq \\
\max u(a+\omega n(\omega)-x(\omega), \omega n(\omega) / w) \\
\omega \in\left\{z \in\left[w_{L}, w_{H}\right] \mid u(z)>\bar{u}(z)\right\} \\
\text { all } w \in\left[w_{L}, w_{H}\right]
\end{gathered}
$$

The constraints (7) are of the same form as in the classic Mirrlees (1971) optimal tax problem, and represent the means-tests that may enhance collections. Any borrower $w$ has to earn income $\omega n(\omega)$ in order to be eligible for the payment amount $x(\omega)$. The incentive constraint requires that the payment amount $x(\omega)$ not be so low that type $w$ would choose to earn $\omega n(\omega)$ rather than $w n(w)$.

Lenders cannot ask borrowers to pay more than $b$ or supply less than zero effort:

$$
x(w) \leq b, n(w) \geq 0
$$

Lenders choose effort and repayment profiles $n(w)$ and $x(w)$, respectively, to maximize (5) subject to the constraints (6), (7), and (8).

Given a solution to the collection-maximization program, equilibrium effort profiles $n(w)$ and income profiles $y(w)$ are calculated from the program for those types receiving modified payments, and as the efficient effort for those types foreclosed or paying in full. A collection schedule $x(y)$ supporting the equilibrium is calculated by inverting the income profile $y(w)$ and substituting it into the payment profile $x(w){ }^{29}$

The first step in finding a solution the collection-maximization program is to guess as to which of the many incentive constraints bind. As in the classic Mirrlees problem, there may be an interval $\left[w_{2}, w_{3}\right]$ of the productivity distribution over which only the local incentive constraints bind, and in the downward direction. In other words, each type $w \in\left[w_{2}, w_{3}\right]$ will be indifferent between his own income and repayment $(w n(w), x(w))$ and the income and repayment assigned by the lender to someone with marginally less productivity. He will strictly prefer his income and repayment to the

\footnotetext{
${ }^{29}$ I refer to mappings from productivity to outcomes as "profiles" and mappings from incomes to outcomes as "schedules." As shown below, the optimal income profile will be invertible, except over ranges in which the payment profile $x$ is constant.
} 
income and repayment assigned to all other types. On this interval, the binding incentive constraints have a differential form:

$$
\frac{d u(w n(w)-x(w), n(w))}{d w} \geq-u_{n}(n(w)) \frac{n(w)}{w}
$$

where $u_{n}$ denotes the marginal disutility of effort, which depends on the level of effort. The integral form is:

$$
u(w n(w)-x(w), n(w))-u\left(w_{2} n\left(w_{2}\right)-x\left(w_{2}\right), n\left(w_{2}\right)\right)+\int_{w_{2}}^{w} u_{n}(n(z)) \frac{n(z)}{z} d z \geq 0
$$

$w \in\left[w_{2}, w_{3}\right]$

Over intervals of the productivity distribution in which payments are independent of income - such as those in which foreclosures occur or full payments are made - the local incentive constraints do not bind.

The participation constraint is less familiar from the optimal tax literature, but may create an interval over which the local incentive constraints above do not bind and global constraints do. For example, it may be optimal to induce a mass point in the income distribution: a range of productivities all assigned the same income and repayment. An income mass point is especially likely for the productivities on the margin of foreclosure because those choosing foreclosure are on a portion of the budget constraint with slope $w$ in the $[n, c]$ plane (slope 1 in the $[y, c]$ plane) whereas those making payments may face a lesser slope due to the means test. In this case, the binding incentive constraints can be represented as:

$$
w n(w) \leq w_{2} n\left(w_{2}\right), \quad w \in\left[w_{1}, w_{2}\right]
$$

Although the FDIC-HASP plan may not obtain the maximum lender collections, the allocation it induces does help illustrate some of the incentive and participation constraints that restrict collections. FDIC-HASP induces an allocation that can be described by partitions of the productivity distribution at two points $w_{1}>w_{2}$. Those with productivity in bottom interval $\left[w_{L}, w_{1}\right]$ repay none of the (unsecured part of) their 
mortgage and are foreclosed; they choose allocations on the segment WZ in Figure 2. The participation constraint binds on this interval. Those in the interval $\left[w_{1}, w_{2}\right]$ all earn the same income and repay the same amount to the lender; they choose the allocation $W_{0}$ in Figure 2. The incentive constraints (11) bind on this interval. Participation constraints bind on the interval $\left[w_{2}, w_{H}\right]$, where the borrowers repay in full.

None of the local incentive constraints bind under the FDIC-HASP, which by itself suggests that it is not maximizing collections. Figure 3 illustrates this result with its "demand curve" analogy. The FDIC-HASP collection profile (not shown in the Figure) would simply be two horizontal lines: one at the left at vertical position $b$, and a second in the middle horizontally, and at vertical position corresponding to the minimum payment $x_{\min }$ on the unsecured part of the mortgage that is accepted by FDIC-HASP. ${ }^{30}$ Figure 3's red curve also includes two horizontal lines, but potentially enhances revenue by having a gradual transition from full payment $b$ to the minimum payment amount. ${ }^{31}$

The collection-maximizing mechanism may include as many as four productivity intervals partitioned by $w_{1}>w_{2}>w_{3}$. Three of those intervals are qualitatively the same as under FDIC-HASP: $\left[w_{L}, w_{1}\right],\left[w_{1}, w_{2}\right]$, and $\left[w_{3}, w_{H}\right] .{ }^{32}$ But the collection-maximum may also involve an interval absent from FDIC-HASP: the interval $\left[w_{2}, w_{3}\right]$ with a graduallysloping repayment profile and binding local incentive constraints (9).

The participation constraints are automatically satisfied on the interval $\left[w_{L}, w_{1}\right]$, because those types are foreclosed. If a participation constraint were binding in the interval $\left[w_{1}, w_{2}\right]$, then it can only bind at $w_{1}$ because (among those in the interval) that type supplies the most effort. ${ }^{33}$ The utility surplus relative to foreclosure could either rise or fall with productivity on the interval $\left[w_{2}, w_{3}\right]$, depending on the foreclosure cost gradient on that interval and the marginal tax rates that satisfy the first order conditions.

\footnotetext{
${ }^{30}$ Recall that Figure 2 is drawn with the assumption that FDIC-HASP would (depending on borrower income) accept as little as zero payment on the unsecured part of the mortgage.

${ }^{31}$ With perfect information the collection-maximizing repayment profile would follow the foreclosure cost distribution. Otherwise, the incentive and participation constraints require that Figure 3's red repayment curve be below the "demand curve" and slope downward sufficiently slowly.

${ }^{32}$ The collection-maximizing numerical values for $w_{1}$ and $w_{2}$ do not necessarily coincide with those from the FDIC-HASP plan. It is also possible that some of the intervals $\left[w_{L}, w_{1}\right],\left[w_{1}, w_{2}\right],\left[w_{2}, w_{3}\right]$, or $\left[w_{3}, w_{H}\right]$ must be degenerate in order to maximize collections.

${ }^{33}$ The utility surplus relative to foreclosure also rises with productivity on the interval $\left[w_{3}, w_{H}\right]$ because all types are paying the same $x_{3}$ and have undistorted effort whereas foreclosure costs are rising with productivity.
} 
Suppose the participation constraint were binding at $w_{1}$. Even if the surplus were lower at $w_{3}$ than at $w_{2}$ (where it would be strictly positive), it might still be positive at $w_{3}$. Thus, I proceed by assuming that participation binds only at $w_{1}$ and then confirm that the proposed solution satisfies the participation constraint at $w_{3}$, in which case the participation constraint would be satisfied everywhere. ${ }^{34}$ Income cannot jump down at $w_{1},{ }^{35}$ and foreclosure does not distort the supply of effort, so the participation constraint is simply $x_{1}=\min \left\{m\left(w_{1}\right), b\right\}$.

Assuming for the moment that the participation constraint does not bind at $w_{3}$ and that $m\left(w_{1}\right)<b$, maximizing collections is equivalent to maximizing the Lagrangian:

$$
\begin{aligned}
& L=\int_{w_{1}}^{w_{2}} m\left(w_{1}\right) f(w) d w+\int_{w_{2}}^{w_{3}} x(w) f(w) d w+\int_{w_{3}}^{w_{H}} x_{3} f(w) d w \\
&+\int_{w_{2}}^{w_{3}}\left\{\left[u(w)-u\left(w_{2}\right)\right] q(w)-Q(w)(\gamma n(w))^{\phi} \frac{n(w)}{w}\right\} d w \\
& u(w) \equiv w n(w)-x(w)-\gamma^{\phi} \frac{n(w)^{1+\phi}}{1+\phi}, \quad Q(w) \equiv \int_{w}^{w_{H}} q(z) d z
\end{aligned}
$$

The choice variables are $x(\bullet) \leq b, n(\bullet) \geq 0, x_{3} \leq b, w_{1} \in\left[w_{L}, w_{H}\right]$ and $w_{3} \in\left[w_{L}, w_{H}\right]$. Given $w_{1}$ and $w_{3}, w_{2}$ is inferred from smooth pasting (i.e., that $w_{2} n\left(w_{2}\right)$ is the same regardless of whether it is calculated from above or below).

The Lagrangian's first three terms are repayments in three intervals of productivity in which borrowers make some repayment, imposing the participation constraint $x_{1}=m\left(w_{1}\right)$ and the (global) incentive constraints $x(w)=x_{1}$ for all $w \in\left[w_{1}, w_{2}\right]$. The Lagrangian's last term combines the various local incentive constraints that bind in the interval $\left[w_{2}, w_{3}\right]$; each local constraint has multiplier $q(w) .{ }^{36}$

\footnotetext{
${ }^{34}$ Because the shape of the foreclosure cost function $m(w)$ affects the solution proposed below only at $w_{1}$, a proposed solution could be made to satisfy the participation constraint at $w_{3}$ merely by assuming that the foreclosure cost function were steep enough on $\left(w_{1}, w_{3}\right]$.

${ }^{35}$ If income jumped down at $w_{1}$, constraint (11) would be violated: some of those with productivity less than $w_{1}$ would prefer to earn the same as a person with productivity greater than $w_{1}$ because doing so takes less effort and makes them eligible for modification.

${ }^{36}$ The multipliers are $q(w)=0$ on $\left(w_{3}, w_{H}\right]$.
} 
Substitution for the utility surplus on $\left[w_{2}, w_{3}\right]$ changes the Lagrangian from (12)

to:

$$
\begin{aligned}
L & =m\left(w_{1}\right)\left[F\left(w_{2}\right)-F\left(w_{1}\right)\right]+\left[1-F\left(w_{3}\right)\right] x_{3} \\
& +\left\{m\left(w_{1}\right)-\frac{w_{1}^{(1+\phi) / \phi}}{\gamma}\left[1-\frac{1}{1+\phi}\left(\frac{w_{1}}{w_{2}}\right)^{1+\phi}\right]\right\}\left[Q\left(w_{2}\right)-Q\left(w_{3}\right)\right] \\
& +\int_{w_{2}}^{w_{3}}\left\{x(w) f(w)+[w n(w)-x(w)] q(w)-\gamma^{\phi} \frac{n(w)^{1+\phi}}{1+\phi}\left[q(w)+\frac{1+\phi}{w} Q(w)\right]\right\} d w
\end{aligned}
$$

The Lagrangian (13) is rising in $x_{3}$, unless $w_{3}=w_{H}$, which proves

Proposition 1 The collection-maximizing payment profile $x(w)$ either forgives all borrowers $(x(w)<b$ for all $w)$ or requires full payment $b$ from an interval of borrowers $\left[w_{3}, w_{H}\right]$.

From the first order condition with respect to $x(w), w \in\left[w_{2}, w_{3}\right]$, the multiplier on their local incentive constraint must be $q(w)=f(w)$. It follows that the co-state variable $Q(w)$ is $F\left(w_{3}\right)-F(w)$.

The first order conditions with respect to effort $n(w)$ help describe the effects of unsecured debt collection on the labor market. The conditions with respect to $w_{1}$ and $w_{3}$ help describe the effects of unsecured debt collection on foreclosures.

\section{III.The Labor Market with Maximum Collections, FDIC-HASP, and No Discrimination}

Effort supply is efficient $\left(n(w)=w^{1 / \phi} / \gamma\right)$ on $\left[w_{\mathrm{L}}, w_{1}\right]$ and $\left[w_{3}, w_{H}\right]$. On the interval $\left[w_{1}, w_{2}\right]$, all borrowers have the same income, so $n(w)=n\left(w_{1}\right) w_{1} / w$. Collectionmaximizing effort on $\left[w_{2}, w_{3}\right]$ is found from the first order condition with respect to $n(w)$, so the collection-maximizing effort profile is: 


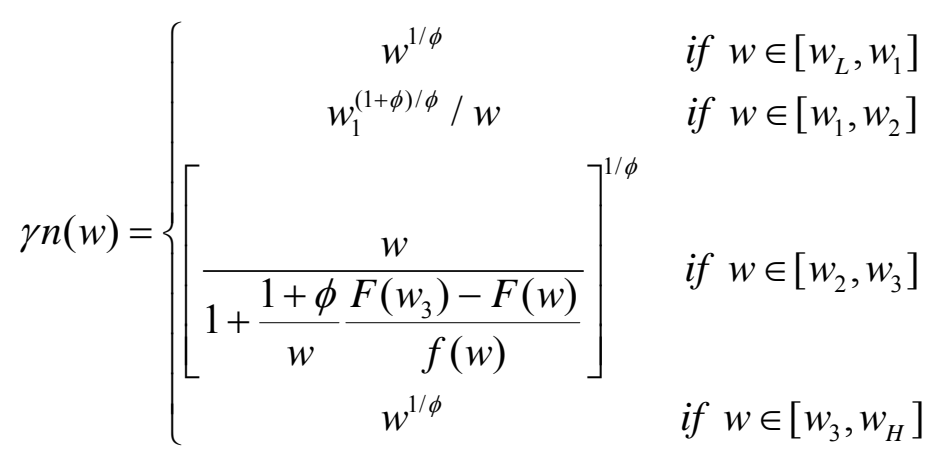

Another way to describe the collection-maximizing effort profile is in terms of the marginal tax rate: the percentage gap between productivity and the marginal rate of substitution associated with the collection-maximizing effort allocation:

$$
\tau(w)=\left\{\begin{array}{cc}
0 & \text { if } w \in\left[w_{L}, w_{1}\right] \\
1-\left(w_{1} / w\right)^{1+\phi} & \text { if } w \in\left[w_{1}, w_{2}\right] \\
1-\left[1+\frac{1+\phi}{w} \frac{F\left(w_{3}\right)-F(w)}{f(w)}\right]^{-1} & \text { if } w \in\left[w_{2}, w_{3}\right] \\
0 & \text { if } w \in\left[w_{3}, w_{H}\right]
\end{array}\right.
$$

The collection-maximizing marginal tax rate profile is shown in Figure 4. It is zero on $\left[w_{\mathrm{L}}, w_{1}\right]$ and $\left[w_{3}, w_{H}\right]$, rising on $\left[w_{1}, w_{2}\right]$, and falling on $\left[w_{2}, w_{3}\right]$. Not surprisingly, collection-maximizing marginal tax rates fall with the elasticity $1 / \phi$ of effort supply with respect to productivity. The formula (15) proves:

Proposition 2 The collection-maximizing marginal tax rate is always less than 100 percent.

There exists a payment schedule $x(y)$, with $x^{\prime}(y) \leq 0$ and $x(y) \leq b$ that supports the collection-maximizing allocation described above. In other words, this payment schedule represents a series of means-tests: lesser payments are required from borrowers with lesser incomes, and only those (if any) with the highest incomes are required to pay in full. When enough of the mortgage is unsecured $\left(b>m\left(w_{L}\right)\right)$, collections are maximized by modifying the mortgages, with means-tested conditions for modification. 
The collection-maximizing payment schedule $x(y)$ can be calculated from the results above by integrating the marginal tax rates in the space of incomes. The integral does not generally have a closed form solution, but we know that it is constant over productivity intervals in which the marginal tax rate is zero and incomes are rising, constant over the interval $\left[w_{1}, w_{2}\right]$, and falling less than one-for-one over the interval $\left[w_{2}, w_{3}\right]$. This means that the budget constraint induced by the collection-maximizing policy has a shape like in Figure 5: sloping downward throughout, linear for the highest and lowest incomes, and concave in the middle. ${ }^{37}$

Compare Figures 2 and 5. Both plans induce budget constraints that have a kink like the one at point $W$. The FDIC-HASP plan presents borrowers with marginal tax rates that are either zero or 100 percent (or more). ${ }^{38}$ The collection-maximizing policy presents borrowers with a range of marginal tax rates that includes zero and excludes 100 percent. Both plans induce an inefficient amount of effort by at least some of the borrowers.

If lenders were constrained to maximize collections without discriminating - that is, demanding a single payment amount $x$ from all borrowers with the same $b$ - then the supply of effort would be efficient at all points in the productivity distribution, although collections would not be maximized. Assuming that the constraint $x \leq b$ does not bind, lender-collections are maximized (conditional on non-discrimination) by reducing mortgage debt from $b$ to $x_{0}$, where $x_{0}$ satisfies a familiar unit-elastic condition:

$1=\frac{G^{\prime}\left(x_{0}\right) x_{0}}{1-G\left(x_{0}\right)}$

where $G$ is the distribution of foreclosure costs, which is $G(x) \equiv F\left(m^{-1}(x)\right)$ when foreclosure costs are simply $m(w)$. All borrowers with $m(w)<x_{0}$ choose not to pay $x_{0}$ and

\footnotetext{
${ }^{37}$ All borrowers are presented with the same modification schedule, so the budget constraint is the same for incomes above the minimum threshold $y_{W}$. Below $y_{W}$, the constraint depends on the foreclosure cost, which varies across borrowers; Figure 5 graphs the case of a borrower with productivity greater than $w_{1}$.

${ }^{38}$ Assuming that effort is a bad and consumption a good (and ignoring optimization error), any behavior induced by budget set with tax rates in excess of $100 \%$ can also be induced by a budget set with $100 \%$ marginal tax rates.
} 
are foreclosed; the collection-maximizing foreclosure rate without discrimination is $F\left(m^{-1}\left(x_{0}\right)\right)$.

When lenders can discriminate, more is collected and effort is distorted. Collections are just a transfer from borrowers to lenders, so means-tests have a deadweight cost in the form of inefficient effort supply. Foreclosures are also a deadweight cost, so the next question to address is whether means-tests reduce foreclosures at all, and enough to offset the effort distortions.

\section{IV.Foreclosures and Deadweight Costs Under the Three Policies}

Because the FDIC-HASP plan modifies some of the mortgages, it creates fewer foreclosures (and more effort distortion) than a collection policy that demanded payment in full. However, that full-payment counterfactual is of limited relevance because it is likely not in lenders' interest. The purpose of this section is to quantify the relative foreclosures and deadweight costs under three collection policies: FDIC-HASP, collection-maximizing with discrimination, and collection-maximizing without discrimination. The results depend on the amount $b$ of negative equity, so the results are stated conditional on a particular value - or range of values - for $b$, and summarized in Table 1.

\section{IV.A. Collection-Maximizing Foreclosures, without Discrimination}

Recall that the number $r_{0}$ of foreclosures consistent with the non-discriminatory collection-maximizing policy is $r_{0}=F\left(m^{-1}\left(\min \left\{x_{0}, b\right\}\right)\right)$, where $x_{0}$ is the payment satisfying the unit elasticity condition $(3)$ and $F\left(m^{-1}(\cdot)\right)$ is the distribution function for foreclosure costs. Even if lenders could not discriminate, they would likely modify mortgages because their gain from reducing foreclosures may exceed the lost revenue from those willing to pay in full.

For $b \leq m\left(w_{L}\right)$, the foreclosure rate is zero because all borrowers prefer paying in full to foreclosure. For $b \in\left[m\left(w_{L}\right), x_{0}\right], r_{0}=F\left(m^{-1}(b)\right)$, which rises with $b$. For $b>x_{0}, r_{0}=$ $F\left(m^{-1}\left(x_{0}\right)\right)$. Figure 6's dotted line graphs the (non-discriminatory) collection-maximizing foreclosure rate as a function of $b$. 


\section{IV.B. Foreclosures and Home Values under FDIC-HASP}

FDIC-HASP modifies mortgages only for borrowers with incomes in an interval $\left[y_{W}, y_{Y}\right]$. Borrowers outside that interval either pay in full or invite foreclosure. If FDICHASP were fully enforced, foreclosures (if any) would result only from households that earn less than the minimum income threshold, which likely falls with the amount underwater. Recall from Figure 2 that the minimum annual income threshold $y_{W}$ is:

$$
y_{W}=\frac{h-\left(b-x_{\min }\right) / R}{0.31}
$$

where $h$ is the annual housing payment, $b$ is the amount underwater, $x_{\min }$ is the minimum payment (e.g., Figure 2 displays the case of $x_{\min }=0$ ) required from those receiving modification, and $R$ the present value of one dollar paid for each of the next five years. ${ }^{39}$ The term in parentheses is the maximum amount that loans will be modified under FDICHASP. The minimum income threshold $y_{W}$ can be as large as $h / 0.31$, which I assume to be large enough that it exceeds the income efficiently supplied by a borrower with productivity $w_{L}$.

For $b \leq m\left(w_{L}\right)$, the foreclosure rate is zero because all borrowers (including those earning less than $y_{W}$ ) prefer paying in full to foreclosure. The foreclosure rate could also be zero because the income threshold is so low. Otherwise, as $b$ rises above $m\left(w_{L}\right)$, the lowest productivity borrowers are foreclosed because that is better for them than full payment, and they prefer not to earn as much as $y_{W}$. The foreclosure rate in this case is $F\left(m^{-1}(b)\right)$, as it is when collections are maximized without discrimination. The Appendix proves:

\footnotetext{
${ }^{39}$ I assume that $x_{\min }$ is no larger than the minimum payment $m\left(w_{L}\right)$ required by collection maximizers when $b$ is close to zero, so that slightly underwater mortgages are eligible for modification under FDIC-HASP. Eligibility requirements articulated by the Administration's internet site (www.makinghomeaffordable.gov; see also www.mtgprofessor.com) suggest that modification or refinancing terms (more generous than available in the market) are available even for mortgages that are slightly under water.
} 
Proposition 3 If the minimum foreclosure cost $m\left(w_{L}\right)$ is small enough relative to the full annual housing payment $h$ that type $w_{L}$ prefers foreclosure to earning enough to be eligible for the minimum modified payment required by FDIC-HASP, then, for an interval of $b$ including 0 and $m\left(w_{L}\right)$, (i) FDIC-HASP results in a foreclosure rate that is at least as great as the non-discrimination foreclosure rate and (ii) effort is distorted by FDIC-HASP.

The condition of the proposition holds when either $m\left(w_{L}\right)$ or the effort supply elasticity $1 / \phi$ are sufficiently small, and must hold if the foreclosure rate under FDIC-HASP were known to be positive.

For $b$ small, but larger than $x_{\text {min }}$, FDIC-HASP offers means-tested modification and thereby distorts the supply of effort. Both collection policies result in the same foreclosure rate (see also the "FDIC" and "Non-disc" curves in Figure 6), which may be positive or zero depending on how $b$ compares to $m\left(w_{L}\right)$. Thus, in this range, FDICHASP distorts effort without "saving homes," as compared to the debt collection policy that would maximize collections without discrimination.

For larger $b$, FDIC-HASP always distorts effort, but the effect of FDIC-HASP on the foreclosure rate relative to the non-discrimination policy can be positive or negative depending on the sizes of the minimum income threshold $y_{W}$ and the maximum foreclosure rate $F\left(m^{-1}\left(x_{0}\right)\right)$ under no-discrimination. When the amount of negative equity gets large enough, FDIC-HASP not only distorts the supply of effort in order to avoid modifying mortgages for high income borrowers, but it also distorts the supply of effort in order to reduce foreclosures below what they would be at smaller amounts of negative equity. All else equal, a reduction in home values in this range will increase the likelihood that an already underwater mortgage will avoid foreclosure via FDIC-HASP modification because the income threshold $y_{W}$ falls with home values and is binding for borrowers on the margin of foreclosure. ${ }^{40}$ This is shown in Figure 6 as downward sloping sections of the "FDIC" and "FDIC" curves.

\footnotetext{
${ }^{40}$ A reduction in home values will also increase the fraction of borrowers who are under water, which by itself increases foreclosures. Empirically, home values will be correlated with other determinants of foreclosures, which means that the correlation between home values and foreclosures could be negative even while the causal effect of home values on foreclosures through FDIC-HASP is positive.
} 
Depending on the elasticity properties of the foreclosure cost distribution $F\left(m^{-1}(x)\right)$, the FDIC curve could begin to slope down at $b$ greater than $x_{0}$ (as with Figure 6's "FDIC" curve), or less than $x_{0}$ (as with Figure 6's "FDIC" curve). In the former case, FDIC-HASP induces a greater foreclosure rate than would maximizing collections without discrimination.

\section{IV.C. Foreclosures with Collection-Maximizing Means-Tests}

The first order conditions with respect to $w_{1}$ and $w_{3}$, and the smooth pasting condition, determine the collection-maximizing $w_{1}, w_{2}$, and $w_{3}$. The collectionmaximizing foreclosure rate is $F\left(w_{1}\right)$. When the constraint $x_{3} \leq b$ binds (that is, at least some borrowers pay in full), the conditions are:

$$
\begin{aligned}
& \left(\frac{w_{2}}{w_{1}}\right)^{1+\phi}=1+\frac{1+\phi}{w_{2}} \frac{F\left(w_{3}\right)-F\left(w_{2}\right)}{f\left(w_{2}\right)} \\
& m^{\prime}\left(w_{1}\right) \frac{F\left(w_{3}\right)-F\left(w_{1}\right)}{f\left(w_{1}\right)}-m\left(w_{1}\right)-\frac{F\left(w_{3}\right)-F\left(w_{2}\right)}{f\left(w_{1}\right)} \frac{1+\phi}{\phi} \frac{w_{1}^{1 / \phi}}{\gamma}\left[1-\left(\frac{w_{1}}{w_{2}}\right)^{1+\phi}\right]=0 \\
& b-m\left(w_{1}\right)+\frac{w_{1}^{(1+\phi) / \phi}}{\gamma}\left[1-\frac{1}{1+\phi}\left(\frac{w_{1}}{w_{2}}\right)^{1+\phi}\right]=\frac{w_{3}^{(1+\phi) / \phi}}{\gamma} \frac{\phi}{1+\phi}
\end{aligned}
$$

The first condition requires that effort and incomes are continuous functions of $w$ at $w=$ $w_{2}$. The second condition and third conditions require that, at the optimum, $w_{1}$ and $w_{3}$ have zero marginal effects on collections, respectively. The Appendix proves

Lemma If $b \leq m\left(w_{L}\right)$, the optimum is $w_{1}=w_{2}=w_{3}=w_{L}$.

Proposition 4 uses these conditions to show that the discrimination that maximizes collections can reduce foreclosures, but the discrimination associated with FDIC-HASP does not. 
Proposition 4 Over a range for $b$ that begins at, but does not include, $b=m\left(w_{L}\right)$, foreclosures are zero for the collection-maximizing policy with discrimination, but strictly positive for the non-discrimination allocation. If the minimum foreclosure cost $m\left(w_{L}\right)$ is small enough relative to the full annual housing payment $h$ that type $w_{L}$ prefers foreclosure to earning enough to be eligible for the minimum modified payment required by FDIC-HASP, then FDIC-HASP foreclosures are also strictly positive.

Proof The strictly positive foreclosure rates under FDIC-HASP and nondiscrimination are shown in Proposition 3. The last condition (17) above is the first order condition with respect to $w_{3}$, which is exactly zero at $w_{1}=w_{2}=w_{3}=w_{L}$ and $b=m\left(w_{L}\right)$. The middle condition is the derivative of the Lagrangian (13) with respect to $w_{1}$, divided by $f\left(w_{1}\right)$, and is equal to $-b$ at $w_{1}=w_{2}=w_{3}=w_{L}$ and $b=m\left(w_{L}\right)$. Thus, a marginal increase in $b$ in the neighborhood of $b=m\left(w_{L}\right)$ will marginally increase $w_{2}=w_{3}$, but $w_{1}$ will remain equal to $w_{L}$.

The proposition has a lot in common with a familiar proposition in public finance: the deadweight cost of the first dollar of income taxation is zero. To see this, note that lenders can collect $b$ without any distortions when $b \leq m\left(w_{L}\right)$, because all borrowers would rather pay in full than pay their foreclosure cost. When $b$ exceeds $m\left(w_{L}\right)>0$, lenders can collect more than $m\left(w_{L}\right)$ only by distorting on one margin or another. Assuming that the unit elasticity condition (3) does not hold at $x=m\left(w_{L}\right)$, the marginal deadweight cost of raising revenue by increasing foreclosures (and thereby inducing other borrowers to pay more) is strictly positive, whereas the marginal deadweight cost of distorting incentives (and thereby raising the amount that high income borrowers pay) is zero. Thus, lenders who can discriminate do not use foreclosures to collect the first amounts of revenue. ${ }^{41}$

\footnotetext{
${ }^{41}$ Because the deadweight costs of means-tests are convex in the amount collected, efficient revenue collection requires that the mix of foreclosures and means tests shift toward foreclosures as the unsecured amount owed $b$ increases. FDIC-HASP does the opposite when $b$ rises: it increases the fraction of borrowers at point $W_{0}$ in Figure 2 not only to obtain more revenue for lenders, but also to reduce foreclosures. Given that FDIC-HASP is less efficient than non-discrimination at small $b$, its inefficient mix of foreclosures and means-tests tends to makes its relative efficiency even worse at large $b$.
} 
Figure 6's "C-max" curve displays the comparative statics of the collectionmaximizing foreclosure rate with respect to $b$, and shows how they compare to the comparative statics under the two other collection policies. Table 1 displays further comparative statics for small amounts $b$ of negative equity. The collection-maximizing policy has the least foreclosures, and collects the most. The non-discrimination policy collects the least. FDIC-HASP has the greatest overall deadweight cost, and does not reduce foreclosures relative to either alternative. The Appendix proves:

Proposition 5 Maximizing collections with discrimination results in more collections, but not necessarily less deadweight cost than maximizing collections without discrimination.

\section{Conclusions}

The Bush administration advocated a mortgage modification plan authored by the FDIC, which has been tweaked and further promoted by the Obama administration's Homeowner Affordability and Stability Plan. This paper considers the consequences of this FDIC-HASP plan for the supply of effort and the incidence of foreclosures, and compares those consequences to those that would occur under a plan that maximizes lender collections, and a plan that maximizes lender collections without means-testing.

All three plans reduce foreclosures as compared to leaving the mortgages unmodified. Although the unmodified-mortgage benchmark aids understanding of the economics of mortgage modification, we cannot assume that underwater mortgages would go modified absent the FDIC-HASP plan and its means-tests. Rather, we might expect lenders to modify mortgages in a way that enhances their collections. As compared to the collection-maximizing benchmark, the marginal tax rates implicit in the FDIC-HASP plan - well over 100 percent - are excessive. Moreover, FDIC-HASP needlessly distorts the supply of effort for borrowers with slightly negative home equity, because foreclosure rates among those borrowers would be low (if not zero) under the collection-maximizing plans. 
For some relatively small amounts of negative equity, FDIC-HASP may result in more foreclosures and overall deadweight costs than would a plan that maximizes collections. The collection-maximizing plan uses means tests rather than foreclosures to obtain small collections from the high income borrowers, based on the fact that (from the perspective of a lender and his borrowers) the marginal deadweight costs of mean-tests are initially zero whereas the marginal deadweight costs of foreclosures are positive.

At first glance, small amounts of negative equity would seem irrelevant today because housing prices have fallen so much. However, even in Nevada where underwater mortgages are the most prevalent, "only" half of mortgages are underwater, which means that half are not underwater and presumably many are only slightly underwater. The fact that recent declines in home values have coincided with increases in the fraction of U.S. mortgages underwater shows that many mortgages are slightly underwater. Thus, even if FDIC-HASP enhanced efficiency for deep underwater mortgages (it does not), my result that it harms efficiency for the numerous slightly underwater mortgages means that its aggregate efficiency impact could well be negative.

I have confined my analysis to mortgages, with a basic setup in which one party (a "lender") attempts to collect from a heterogeneous group ("borrowers"), using a threat of punishment ("foreclosure") for nonpayment. With the housing crash and the recession, the unsecured amount to be collected has suddenly increased, and the punishment may have lost some of its pain. As a result, full collections are not made, but rather forgiven for those who appear to have the least ability to pay. This basic setup probably has a lot in common with revenue collection efforts elsewhere in the economy, such as the collection of trade debts, tax debts, student loans, or tuition payments. Indeed, during the writing of this paper, the federal government began to modify student loans, with the borrowers who earn less receiving more loan forgiveness (Glater, 2009). Thus, while millions of workers have seen massive increases in their marginal tax rates during this recession as a result of mortgage modification, additional workers and businesses may also have seen significant increases in their marginal tax rates due to these other collection efforts.

Federal mortgage modification programs create excessive marginal tax rates, but the use of means-tests in the mortgage modification process would occur even without 
government intervention because means-tests are in the collectors' interests. Positive marginal tax rates are thereby created in the private sector, on top of the various income taxes and means-tested benefits perennially administered by federal, state, and local governments. These alternative sources of "taxation" were not explicitly considered in my model, ${ }^{42}$ but a prior economics literature has already shown how tax rates are excessive when multiple collectors have access to the same tax base (Olson, 2000). Thus, it is ironic that the federal government has raised the implicit marginal tax rates associated with mortgage modification, when it would enhance efficiency and its own tax collections by unconditionally repudiating some of the private debts, or at least pushing private collectors to rely less on means-tests than would be in the collectors' interest.

Prohibiting means-tested mortgage modification is not the same as prohibiting modification: it's just that mortgages would have to be modified without means tests. In other words, those borrowers with significantly negative equity would be forgiven regardless of whether they were "able" to pay. In theory, lenders could find it optimal (given that they were not permitted to means test) to write down underwater mortgages so much that foreclosure rates would ultimately be quite low. Of course, a large and acrossthe-board mortgage write-down would dramatically reduce lender collections, but the objectives of efficiency and lender collections are quite different.

\footnotetext{
${ }^{42}$ One approach would be to interpret my "productivity" variable $w$ as a wage rate after various (nonmortgage) taxes.
} 


\section{Appendix: Proofs of Lemma and Remaining Propositions}

Proposition 3 If the minimum foreclosure cost $m\left(w_{L}\right)$ is small enough relative to the full annual housing payment $h$ that type $w_{L}$ prefers foreclosure to earning enough to be eligible for the minimum modified payment required by FDIC-HASP, then, for an interval of $b$ including 0 and $m\left(w_{L}\right)$, (i) FDIC-HASP results in a foreclosure rate that is at least as great as the non-discrimination foreclosure rate and (ii) effort is distorted by FDIC-HASP.

Proof Under the condition of the proposition, there is a range of productivities that includes $w_{L}$ for which the borrowers prefer foreclosure to the allocation $W_{0}$ (see, for Figure 2), and all other borrowers prefer an allocation on the section $O Y W_{0}$ of the budget constraint. Thus, the borrowers foreclosed by FDIC-HASP are limited to those that are both in the aforementioned range of productivities and have foreclosure cost less than $b$; the FDIC-HASP foreclosure rate is $F\left(m^{-1}(b)\right)$. The non-discrimination foreclosure rate is $F\left(m^{-1}\left(\min \left\{b, x_{0}\right\}\right)\right)$, which coincides with $F\left(m^{-1}(b)\right)$ for an interval of $b$ including 0 and $m\left(w_{L}\right)$. FDIC-HASP's distorts effort for any $b>m\left(w_{L}\right)$ because the distribution of productivities is continuous and the point $W_{0}$ in Figure 2 is strictly preferred to the point $W$.

Lemma If $b \leq m\left(w_{L}\right)$, the optimum is $w_{1}=w_{2}=w_{3}=w_{L}$.

Proof At the proposed solution $w_{1}=w_{2}=w_{3}=w_{L}$, the top condition of (17) is satisfied because both right and left sides of the equation are one. The middle condition is the derivative of the Lagrangian (13) with respect to $w_{1}$, divided by $f\left(w_{1}\right)$, and is equal to $-m\left(w_{L}\right)$ at $w_{1}=w_{2}=w_{3}=w_{L}$. Thus, the proposed solution maximizes the Lagrangian with respect to $w_{1} \in\left[w_{L}, w_{H}\right]$. By the same reasoning (see the bottom condition of (17)), the proposed solution maximizes the Lagrangian with respect to $w_{3} \in\left[w_{L}, w_{H}\right]$ because $b$ $m\left(w_{L}\right) \leq 0$. 
Proposition 5 Maximizing collections with discrimination results in more collections, but not necessarily less deadweight cost than maximizing collections without discrimination.

Proof Maximizing collections with discrimination results in more collections by definition. If $x_{0} \leq w_{L}$, then maximizing collections without discrimination has zero deadweight cost (zero foreclosures and no effort distortion) for all values of $b$. Maximizing collections with discrimination has strictly positive deadweight costs as long as that discrimination distorts effort for some of the borrowers. 


\section{Table 1. Efficiency and Revenue Effects of Three Collection Policies}

Small Amounts of Negative Equity

The Table ranks three different debt collection policies by the foreclosure rate, efficiency

distortions, total deadweight costs, and revenue collected

$$
b \in\left(0, m\left(w_{L}\right)\right] \quad b \in\left(m\left(w_{L}\right), x_{0}\right]
$$

$\begin{array}{lcc}\text { Foreclosure Rate } & \text { all policies }=0 & 0 \leq \mathrm{c}-\mathrm{max}<\text { non-disc }<\text { FDIC } \\ \text { Effort Distortions } & 0=\text { non-disc }=\mathrm{c}-\mathrm{max}<\mathrm{FDIC} & 0=\text { non-disc }<\text { c-max }<\text { FDIC } \\ \text { Total Deadweight Costs } & 0=\text { non-disc }=\mathrm{c}-\text { max }<\text { FDIC } & 0<\text { non-disc, c-max }<\text { FDIC } \\ \text { Revenue Collected } & \text { all policies }=b & \text { non-disc }<\text { FDIC }<\text { c-max } \leq b\end{array}$

Notes: "c-max" = Collection-maximization with means-tests

"non-disc" = Collection-maximization without means-tests

"FDIC" = FDIC-HASP modification rules

$b=$ amount of negative equity

$m\left(w_{L}\right)=$ minimum foreclosure cost among borrowers

$x_{0}=$ colleciton-maximizing common payment 
Fig 1. Three Mortgage Payment Scenarios

The Figure displays borrower budget sets for three mortgage payment scenarios: pay in full, foreclosure, and pay only up to the home value. The relative magnitudes of these payments are assumed for the purpose of illustration.

The horizontal axis measures borrower income during the benchmark period, from highest to lowest.

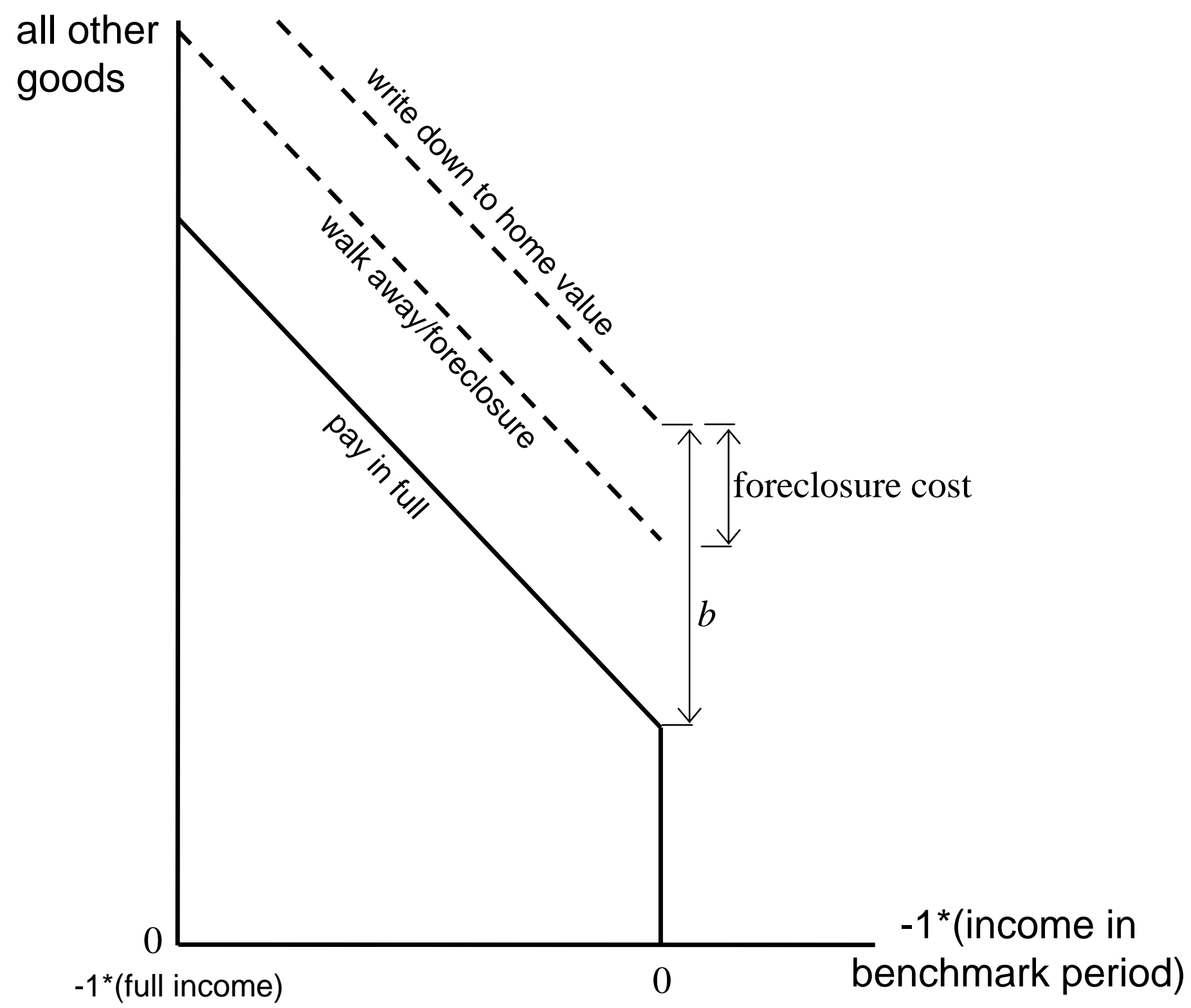


Fig 2. Budget Set Induced by FDIC-HASP Means-Tests

The horizontal axis measures borrower income during the benchmark period, from highest to lowest. $a$ denotes the present value of income available for all other goods, absent: payment $b$ for the unsecured part of the mortgage and benchmark period income.

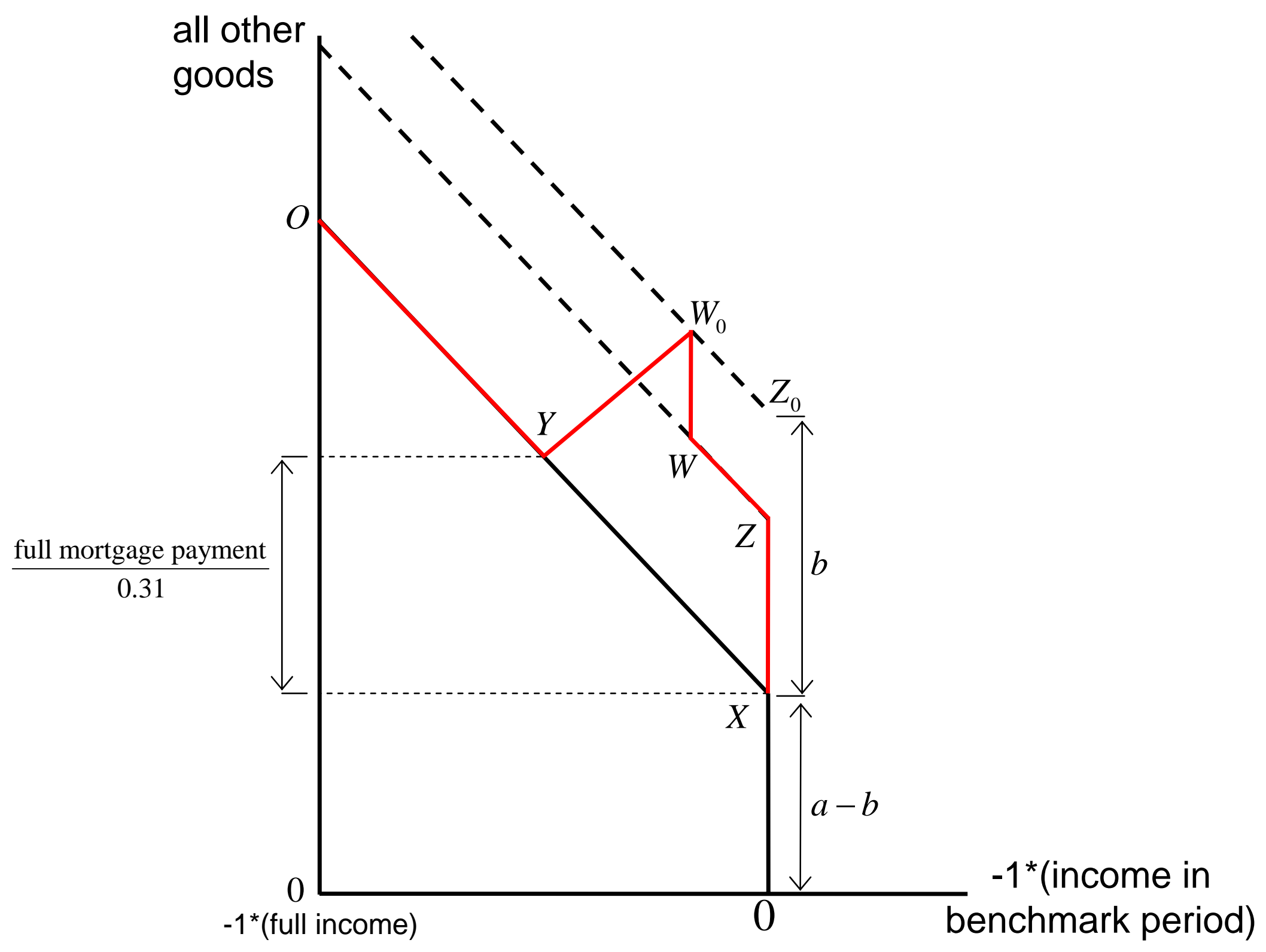


Fig 3. Borrowers' "Demand" for Repayment, Compared with a Means-Tested Collection Policy

The monotone curve graphs the foreclosure cost inverse CDF, from highest cost to lowest.. The other (red) curve shows the amounts collected by the collection-maximizing policy that discriminates on the basis of income.

\section{Foreclosure cost,} repayment amount

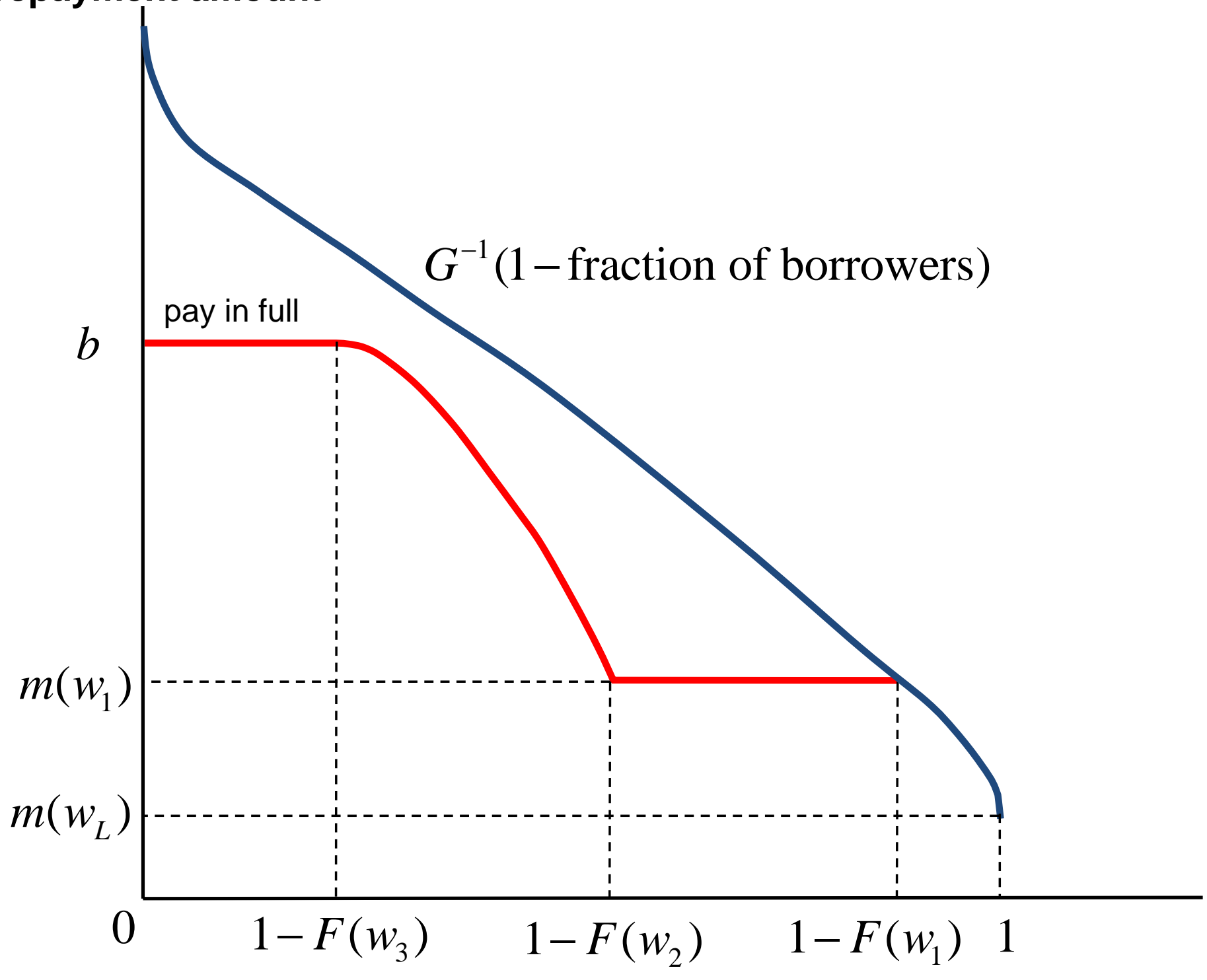


Fig 4. The Profile of Collection-Maximizing Marginal Tax Rates

The collection-maximizing marginal tax rate is graphed as a function of borrower productivity.

The range of borrowers $\left[W_{L}, w_{1}\right]$ and $\left[W_{3}, w_{H}\right]$ are foreclosed or pay in full, respectively.

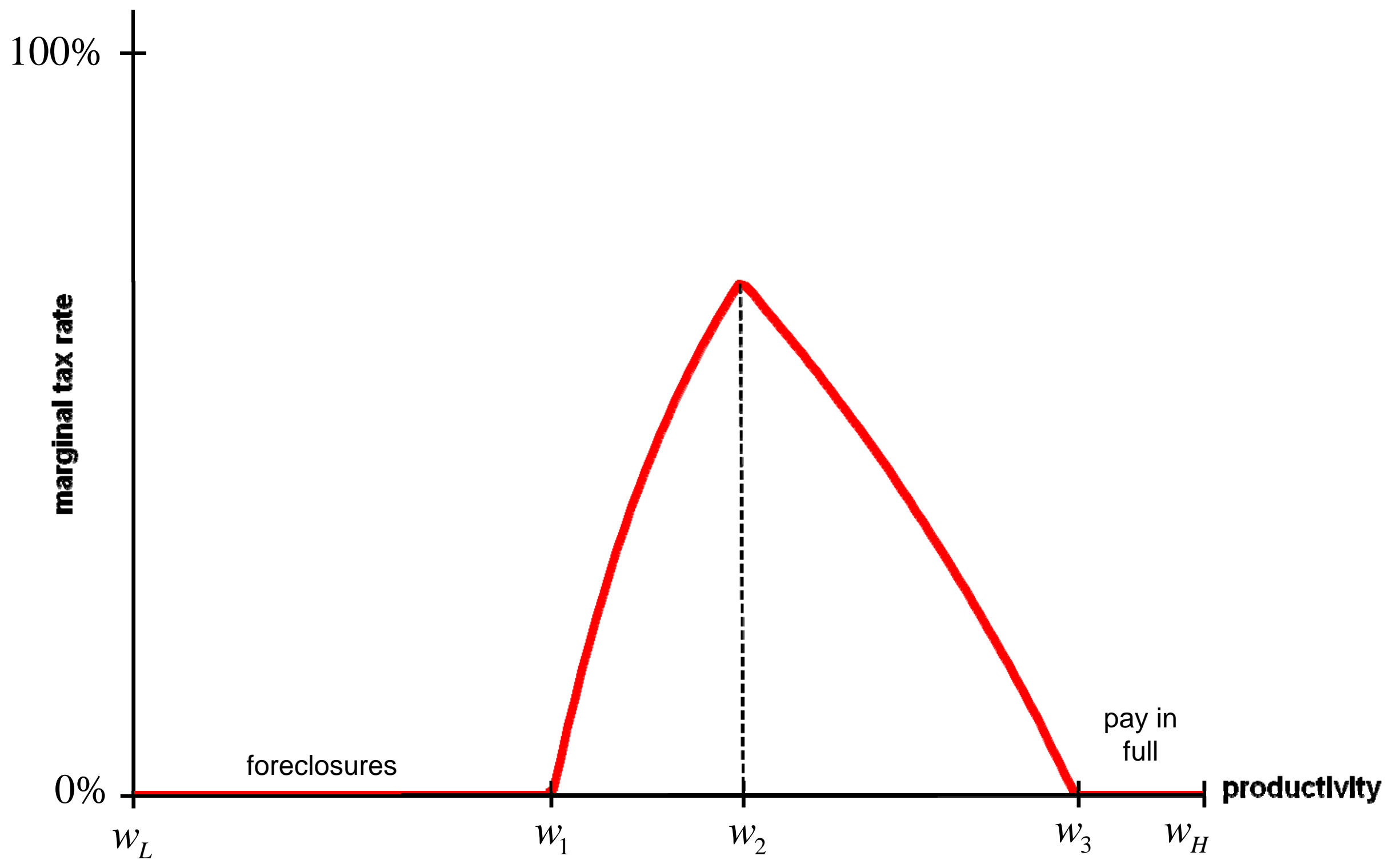




\section{Fig 5. Budget Set Induced by Collection-maximizing Means-Tests}

The budget curve is convex for the range of incomes in which the mortgage is modified.

For the purposes of illustration, the segment nearest zero income is shown for a borrower that is more productive than $w_{1}$.

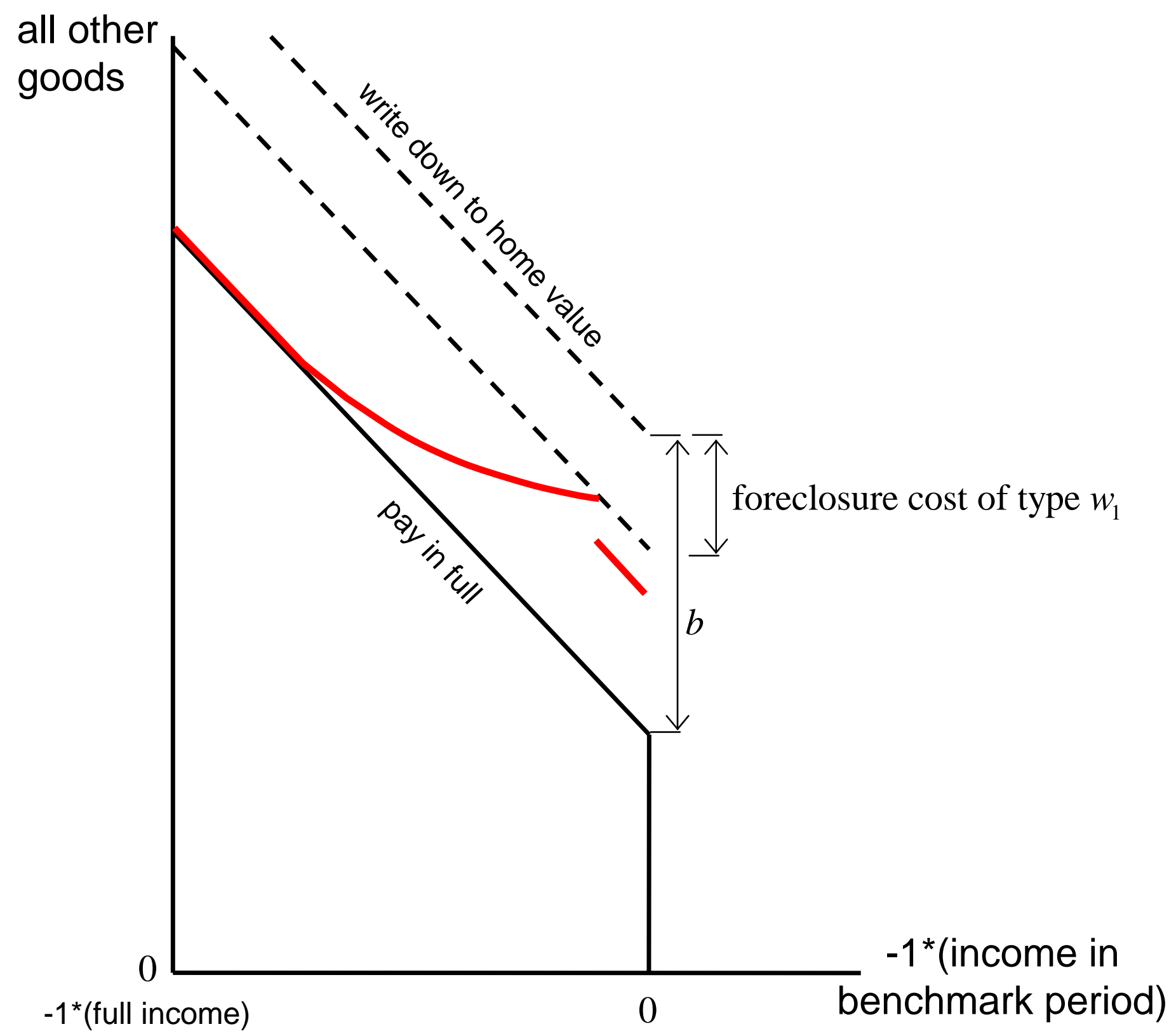


Fig 6. Foreclosure Rate Comparative Statics

\section{with respect to collection plan and amount of negative equity}

"c-max" = Collection-maximization with means-tests, "non-disc" = Collection-maximization without means-tests, "FDIC" = FDICHASP modification rules. Two versions of FDIC are shown, depending on whether its foreclosure rate peaks (with respect to $b$ ) lower

\section{Foreclosure}

rate

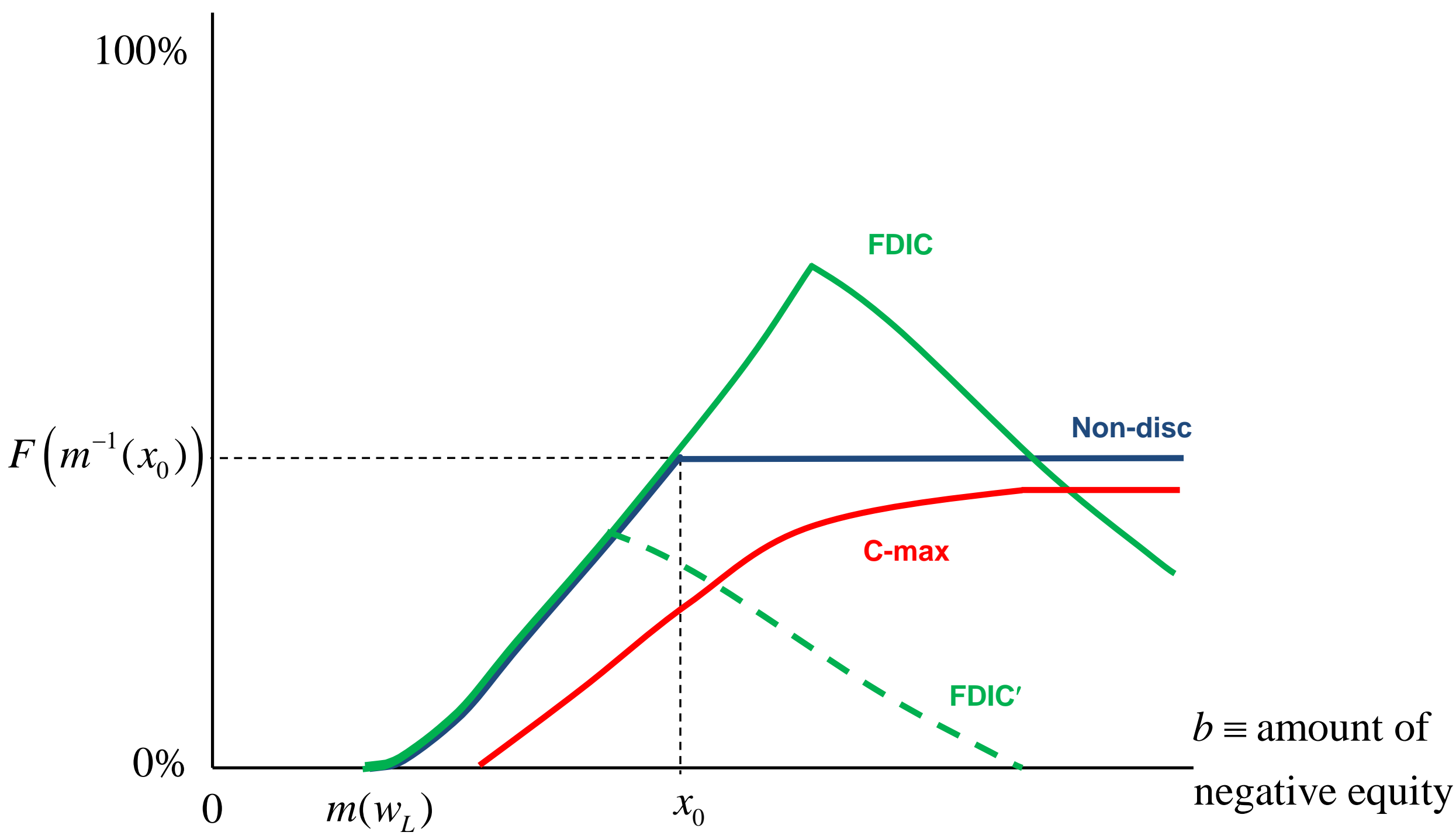




\section{References}

Aversa, Jeannine. "Government Plans Massive Citigroup Rescue Effort." Associated Press. November 24, 2008.

Bernanke, Ben S. "Nonmonetary Effects of the Financial Crisis in the Propagation of the Great Depression.” American Economic Review. 73(3), June 1983: 257-276.

Chetty, Raj and Emmanuel Saez. "Optimal Taxation and Social Insurance with Endogenous Private Insurance.” Manuscript, University of California Berkeley, July 2009.

Chiang, Raymond and Chester S. Spatt. "Imperfect Price Discrimination and Welfare." Review of Economic Studies. 49(2), April 1982: 155-181.

Dick, Andrew W. and Aaron S. Edlin. "The Implicit Taxes from College Financial Aid." Journal of Public Economics. 65(3), September 1997: 295-322.

Edlin, Aaron S. "Is College Financial Aid Equitable and Efficient?" Journal of Economic Perspectives. 7(2), December 1993: 143-158.

Eggert, Kurt. "Comment on Stegman et al's Preventive Servicing." Housing Policy Debate. 18(2), 2007.

Federal Deposit Insurance Corporation. "Loan Modification Program for Distressed Indymac Mortgage Loans.” August 20, 2008. http://www.fdic.gov/consumers/loans/modification/indymac.html

Feldstein, Martin. "Tax Avoidance and the Deadweight Loss of the Income Tax." Review of Economics and Statistics. 81(4), November 1999; 674-680.

Fisher, Irving. "The Debt-Deflation Theory of Great Depressions." Econometrica. 1(4), October 1933: 337-357.

Foote, Christopher, Gerardi, Kristopher and Paul Willen. "Negative Equity and Foreclosure: Theory and Evidence." Journal of Urban Economics. 64, 2008: $345-245$.

Foote, Christopher, Gerardi, Kristopher, Lorenz Goette, and Paul Willen. "Reducing Foreclosures: No Easy Answers.” NBER working paper \#15063, June 2009. 
Geanakopolos, John D. and Susan P. Koniak. "Mortgage Justice is Blind." New York Times. October 30, 2008.

Geanakoplos, John D. and Susan P. Koniak. "Matters of Principal." New York Times. March 4, 2009.

Glater, Jonathan D. "New Plan Ties Reduced College Loan Payments to Income." New York Times. June 29, 2009.

Grochulski, Borys. "Optimal Personal Bankruptcy Design: A Mirrlees Approach." Richmond Federal Reserve Working paper No. 08-5, September 2008.

Han, Song and Wenli Li. "Fresh Start or Head Start: The Effects of Filing for Personal Bankruptcy on Work Effort.” Journal of Financial Services Research. 31, 2007: $123-152$.

Kahn, Charles and Abdullah Yavas. "The Economic Role of Foreclosures." Journal of Real Estate Finance and Economics. 8, 1994: 35-51.

Kroszner, Randall S. "Is it Better to Forgive than to Receive? Repudiation of the Gold Indexation Clause in Long-Term Debt During the Great Depression.” University of Chicago CRSP working paper 481, April 1999.

Leibowitz, Stan. "New Evidence on the Foreclosure Crisis." Wall Street Journal. July 3, 2009, page A13.

Levy, Dan. "U.S. Underwater Mortgages May Reach 30 percent, Zillow Says." August 11, 2009. http://www.bloomberg.com/apps/news?pid=20601103\&sid=a2p zMYkFQFg

Livshits, Igor, James McGee and Michele Tertilt. "Consumer bankruptcy: a fresh start." American Economic Review. 97(1), March 2007: 402-418.

Ljungqvist, Lars and Thomas J. Sargent. "Understanding European Unemployment with a Representative Family Model." Journal of Monetary Economics. 54(8), November 2007: 2180-2204.

Mirrlees, James A. "An Exploration in the Theory of Optimum Income Taxation." Review of Economic Studies. 38(114), April 1971: 175-208.

Mishkin, Frederic S. "The Household Balance Sheet and the Great Depression." Journal of Economic History. 38(4), December 1978: 918-937.

Mulligan, Casey B. "Aggregate Implications of Indivisible Labor." Advances in Macroeconomics. 1(1), 2001: Article 4. 
Mulligan, Casey B. "A Depressing Scenario: Mortgage Debt Becomes Unemployment Insurance.” NBER working paper no. 14514, November 2008.

Office of Thrift Supervision. "OCC and OTS Mortgage Metrics Report. Fourth Quarter 2008.” April 2009.

Olson, Mancur. Power and Prosperity. Oxford: Oxford University Press, 2000.

Rucker, Patrick. "Obama Mulls Rental Option for Homeowners." Reuters. July 14, 2009.

http://www.reuters.com/article/euRegulatoryNews/idUSN1429055220090714

Salanié, Bernard. The Economics of Taxation. Cambridge, MA: M.I.T. Press, 2003.

Sichelman, Lew. "Compassionate Servicing.” Mortgage Banking. February 2001.

United States Department of Treasury. "Homeowner Affordability and Stability Plan:

Executive Summary." February 2009.

White, Michelle and Ning Zhu. "Saving Your Home in Chapter 13 Bankruptcy." NBER Working Paper no. 14179, July 2008. 